\title{
ANTICORPOS CONTRA AGENTES BACTERIANOS E VIRAIS EM SUÍNOS DE AGRICULTURA FAMILIAR DO MUNICÍPIO DE MONTE NEGRO, RO
}

\author{
D.M. Aguiar ${ }^{1}$, G.T. Cavalcante ${ }^{2}$, C.C. Dib ${ }^{3}$, E.M.C. Villalobos ${ }^{4}$, E.M.S. Cunha ${ }^{4}$, M.C.C.S.H. Lara ${ }^{4}$, \\ C.A.R. Rodriguez ${ }^{2}$, S.A. Vasconcellos ${ }^{2}$, Z.M. Moraes $^{2}$, M.B. Labruna ${ }^{2}$, L.M.A. Camargo ${ }^{5}$, S.M. Gennari ${ }^{2}$
}

1Pólo Regional de Desenvolvimento Tecnológico dos Agronegóciosda Alta Sorocabana, CP298, CEP19015-970, Presidente Prudente, SP, Brasil. E-mail: danmoura@aptaregional.sp.gov.br

\section{RESUMO}

Foram avaliados soros de suínos provenientes de propriedades rurais que desenvolvem agricultura familiar no Município de Monte Negro, Rondônia, frente a agentes bacterianos e virais. Para a pesquisa de anticorpos contra Brucella spp., foram utilizados o Antígeno Acidificado Tamponado (AAT), a Soroaglutinação Lenta em Tubos (SAL) e a prova do 2-Mercaptoetanol (2ME). Para a pesquisa de Leptospira spp. utilizou-se a Soroaglutinação Microscópica (SAM) contra 24 sorovares de leptospira. Anticorpos contra Parvovírus Suíno (PVS) foram pesquisados pela Inibição da Hemaglutinação (IH), enquanto que o vírus da Peste Suína Clássica (PSC) e da Doença de Aukeszky (DA) por Ensaio Imunoenzimático (ELISA). Apenas uma (0,9\%) das 104 amostras testadas foi reagente na AAT e nenhuma naSAL e 2-ME. ParaLeptospiraspp. foram testados 88 soros, sendo detectados anticorpos em 29 amostras (32,9\%) e os sorovares mais freqüentes foram Castellonis, Bratislava e Canicola. Foram detectados anticorpos contra PVS em 7,7\% (8/104) dos soros testados. Nenhuma amostra foi reagente para PSC e DA.

PALAVRAS-CHAVE: Brucella spp., Leptospira spp., Parvovírus, Pestivírus, Herpesvirus, suínos.

\section{ABSTRACT}

ANTIBODIES AGAINST BACTERIAL AND VIRAL AGENTS IN SWINE FROM FAMILY-RUN FARMS IN MONTE NEGRO COUNTY, STATE OF RONDÔNIA, BRAZIL. Sera from swine from family-employed farms in Monte Negro County, state of Rondônia, Brazil, were evaluated against bacterial and viral agents. Brucellosis was evaluated by Rose-Bengal agglutination (RBA), standard tube agglutination (STA), and mercaptoethanol (ME); and leptospirosis by microscopic agglutination test (MAT) against 24 leptospira serovars. Anti-porcine parvovirus antibodies were tested by haemmaglutination inhibition assay, and ELISA technique was used for detection of antibodies against classical swine fever virus and Aujeszky disease virus. Only 1 (0.9\%) from 104 tested sera reacted by RBA, and no samples reacted in STA and ME.Leptospiraspp. antibodies were detected in 29 (32.9\%) of 88 tested sera and the most frequent serovars detected were Castellonis, Bratislava and Canicola. Antibodies against porcine parvovirus were detected in $7.7 \%(8 / 104)$ of the sera. None of the examined samples reacted to classical swine fever virus or Aujeszky disease virus.

KEY WORDS: Brucella spp., Leptospira spp., parvovirus, pestivirus, herpesvirus, swine.

\section{INTRODUÇÃO}

Nas últimas décadas, os sistemas de agricultura familiar vêm registrando um maior aumento de produtividade. Este sistema é caracterizado por uma forma de produção onde predomina a interação entre gestão e trabalho; são os agricultores familiares que dirigem o processo produtivo, dandoênfase na diversificação e utilizando o trabalho familiar (Toscano, 2003). Nestas propriedades, o tamanho dos rebanhos

\footnotetext{
${ }^{2}$ Universidade de São Paulo, Faculdade de Medicina Veterinária e Zootecnia, Departamento de Medicina Veterinária Preventiva e Saúde Animal, São Paulo, SP, Brasil.

${ }^{3}$ Instituto de Zootecnia, São Paulo, SP, Brasil.

${ }^{4}$ Instituto Biológico, Centro de Pesquisa e Desenvolvimento de Sanidade Animal, São Paulo, SP, Brasil.

${ }^{5}$ Universidade de São Paulo, Instituto de Ciências Biomédicas V, São Paulo, SP, Brasil.
} 
é comumente reduzido e procura atender várias finalidades, como produção bovina destinada à produção de carne e leite, criações de pequenos ruminantes, aves e suínos principalmente para o consumo familiar e poupança econômica (reserva de patrimônio) (VeIGA et al., 1996).

A pecuária suína no Município de Monte Negro, $\mathrm{RO}$, representa um importante segmento dentro do programa de agricultura familiar local, estando entre as dez principais fontes de renda dessas propriedades. Nos anos de 1995 e 1996, a produção suína local contemplava 321 propriedades, agregando um valor estimado de $\mathrm{R} \$ 65.600,00$ para o município (INCRA, 2006).

$\mathrm{Na}$ agricultura familiar, cada animal doente, além de representar prejuízo econômico pela queda na produtividade, também significa risco para a saúde dos demais animais, e de humanos, em se tratando de zoonoses (LAu et al., 1997). As informações a respeito das doenças que acometem os animais nos sistemas de produção da agricultura familiar amazônica são escassas (HomEm et al., 2001; Rodriguezet al., 2003; Aguiaret al., 2006, CAvalCANTE et al., 2006). Entretanto, mesmo que determinadas infecções; bacterianas, virais ou parasitárias, sejam bem conhecidas em outros ecossistemas, é bem provável que no ambiente amazônico ocorram especificidades etiológicas e epidemiológicas importantes.

A brucelose e leptospirose suínas são duas importantes doenças de produção animal, responsáveis por prejuízos na esfera reprodutiva, além de serem zoonoses ocupacionais. A brucelose suína no Brasil tem sido ocasionada pela Brucella suis, embora possa ser causada pela B. abortus, quando criados de forma promíscua com bovinos. Por outro lado, a leptospirose pode ser induzida por uma variedade de sorovares, como Pomona, Bratislava, Icterohaemorrhagiae e Canicola (Roxo et al., 1996; Azevedo et al., 2006). Infecções pelo Parvovírus Suíno (PVS) e pelo Herpesvírus suíno (agente da Doença de Aujeszky-DA) foram associadas a falências reprodutivas, leitegadas irregulares e mortalidade de leitões (CunHA et al., 2003; RodriguEz et al., 2003), enquanto que o Pestivírus suíno, causador da Peste Suína Clássica (PSC), tem sido responsabilizado por grandes perdas econômicas na suinocultura mundial, sendo considerado por muitos, uma das mais importantes doenças de suínos (RAdostits et al., 2000).

Neste sentido, o presente trabalho objetivou conhecer o perfil sorológico do rebanho suíno de Monte Negro, Estado de Rondônia, avaliando a presença da infecção por Brucella spp.,Leptospira spp., Parvovírus, Pestivírus e Herpesvírus suínos em propriedades que desenvolvem agricultura familiar.

\section{MATERIAL E MÉTODOS}

\section{Local de estudo}

O estudo foi realizado no Município de Monte Negro, Estado de Rondônia a oeste da Amazônia Brasileira ( $10^{\circ} 18^{\prime} \mathrm{sul}$; $63^{\circ} 14^{\prime}$ oeste). O Município tem uma população estimada de 13.350 habitantes, dos quais a maioria vive de economia rural, em pequenas propriedades. A região é caracterizada por topografia irregular, solos mistos e vegetação equatorial amazônica de terra firme e clima quente e úmido, com pluviosidade elevada (média anual variando entre $1.440 \mathrm{~mm}$ nos meses de novembro a abril e $557 \mathrm{~mm}$ no período seco, de maio a outubro), com temperatura de 25 a $29^{\circ} \mathrm{C}$ e umidade relativa entre 70 a $80 \%$ durante o ano (CAMARGO et al., 2002).

\section{Amostragem e colheita de soro sanguíneo}

Foram amostrados 104 soros de suínos, de diferentes idades, raças, sexo, por conveniência, presentes em 49 propriedades de agricultura familiar, obtidas por ocasião de um estudo prévio de avaliação de leptospirose bovina durante os meses de maio a outubro de 2002 (Aguiar et al., 2006). As amostras de sangue foram colhidas por venopunção da veia cava cranial e os soros obtidos foram estocados a $-20^{\circ} \mathrm{C}$ até o momento das análises.

\section{Pesquisa de anticorpos}

\section{Brucella spp.}

As amostras foram testadas inicialmente pela prova do Antígeno Acidificado Tamponado (AAT), confirmando as reagentes pela Soroaglutinação Lenta em Tubos (SAL) e Soroaglutinação Lenta em Tubos com 2-Mercaptoetanol (2-ME) conforme Altonet al.(1976). Consideraram-se positivas as amostras que apresentaram título maior ou igual a 25 no teste de 2-ME. O antígeno usado foi uma suspensão inativada de $B$. abortus cepa 1119-3, produzida pelo Instituto de Tecnologia do Paraná (TECPAR).

\section{Leptospira spp.}

Do total de amostras colhidas, foram avaliados 88 soros provenientes de 35 fazendas para a detecção de anticorpos anti-Leptospira spp. Foi utilizada a microtécnica de soroaglutinação microscópica (SAM), efetuada em microplacas com leitura direta através de objetiva de longa distância (GALton et al., 1965; Cole Junior et al., 1973) frente a uma coleção de 24 antígenos constituídos por sorovares de leptospiras vivas, cultivadas em meio líquido de EMJH modificado (AzEvedo et al., 2006): Andamana 
Australis, Autumnalis, Bataviae, Bratislava, Butembo, Canicola, Castellonis, Cinoptery, Copennhageni, Grippotyphosa, Hardjo, Hebdomadis, Icterohaemorrhagiae, Javanica, Panama, Pomona, Patoc, Pyrogenes, Sentot, Shermani, Tarassovi, Wolffi e Whitcombi. O sorovar considerado como mais provável de provocar a infeç̧ão foi o que apresentou maior título no exame. Os animais que apresentaram dois ou mais sorovares com títulos idênticos (coaglutinação) foram excluídos desta análise, sendo considerados apenas reatores para a Leptospira spp. O ponto de corte para a triagem foi a diluição de 1:100 (AzEvedo et al., 2006).

\section{Parvovírus suíno}

O sorodiagnóstico da parvovirose suína foi realizado utilizando a técnica de Inibição da Hemaglutinação (IH) (Joo et al., 1976; Rodriguezet al., 2003). O ponto de corte utilizado foi a diluição de 1:8, conforme descrito por RodRiguez et al. (2003).
Pestivírus e Herpesvirus suínos.

Os soros foram testados por um Ensaio Imunoenzimático (ELISA) com o Kit "Ceditest CSFV" (Cedi Diagnostics B.V.) para a pesquisa de anticorpos contra a glicoproteína de envelope GP-55 do vírus da PSC (Pestivírus suíno) segundo recomendações do fabricante. Para a pesquisa de anticorpos contra Herpesvírus suíno, foi utilizado um Kit de ELISA com antígenos provenientes de cultivo celular, desenvolvido pelo Centro Nacional de Pesquisa deSuínos e Aves da EMBRAPA empregado conformeKROEFetal.(1992).

\section{RESULTADOS}

Os resultados obtidos na presente pesquisa estão sumarizados na Tabela1. Dos 104 soros testados para a pesquisa de anticorpos anti-Brucella spp., apenas 1 $(0,9 \%)$ reagiu frente ao AAT. Entretanto, esta amostra não reagiu nos testes de SAL e 2-ME.

Tabela 1 - Freqüência (\%) de reações positivas para a pesquisa de anticorpos contra Brucella spp., Leptospira spp., Parvovírus, Vírus da Peste Suína Clássica e Vírus da Doença de Aujeszky em suínos do Município de Monte Negro, RO, segundo os respectivos exames sorológicos. Monte Negro, RO, 2002.

\begin{tabular}{llrrr}
\hline Agente & Exame sorológico & \multicolumn{2}{c}{ No de animais } & \multirow{2}{*}{ Reagentes } \\
\cline { 3 - 4 } & & Testados & $0^{*}$ & 0 \\
\hline Brucella spp. & AAT, SAL e 2-ME & 104 & 29 & 32,9 \\
Leptospira spp. & SAM & 88 & 8 & 7,7 \\
Parvovírus suíno & IH & 104 & 0 & 0 \\
Pestivírus suíno & ELISA & 104 & 0 & 0 \\
Herpesvírus suíno & ELISA & 104 & & 0 \\
\hline
\end{tabular}

*Considerou-se positiva amostra reagente no teste confirmatório do 2-ME.

Tabela 2 - Número e freqüência de suínos reagentes à microtécnica de Soroaglutinação Microscópica (SAM), para diferentes sorovares de Leptospira spp. em diferentes títulos. Monte Negro, RO, 2002.

\begin{tabular}{|c|c|c|c|c|c|c|}
\hline \multirow[t]{3}{*}{ Sorovar } & \multicolumn{6}{|c|}{ Suínos reagentes $(\mathrm{n}=29)$} \\
\hline & \multicolumn{4}{|c|}{ Título } & \multirow[t]{2}{*}{ Total } & \multirow[t]{2}{*}{$\%$} \\
\hline & 100 & 200 & 400 & 800 & & \\
\hline Castellonis & 3 & 0 & 2 & 0 & 5 & 17,3 \\
\hline Bratislava & 1 & 1 & 1 & 0 & 3 & 10,3 \\
\hline Canicola & 2 & 0 & 1 & 0 & 3 & 10,3 \\
\hline Andamana & 2 & 0 & 0 & 0 & 2 & 6,9 \\
\hline Shermani & 0 & 1 & 0 & 1 & 2 & 6,9 \\
\hline Patoc & 1 & 1 & 0 & 0 & 2 & 6,9 \\
\hline Autumnalis & 1 & 1 & 0 & 0 & 2 & 6,9 \\
\hline Butembo & 2 & 0 & 0 & 0 & 2 & 6,9 \\
\hline Australis & 1 & 0 & 0 & 0 & 1 & 3,4 \\
\hline Hardjo & 0 & 0 & 0 & 1 & 1 & 3,4 \\
\hline Icterohaemorrhagiae & 0 & 1 & 0 & 0 & 1 & 3,4 \\
\hline Tarassovi & 0 & 1 & 0 & 0 & 1 & 3,4 \\
\hline Coaglutinação* & 1 & 3 & 0 & 0 & 4 & 14,0 \\
\hline
\end{tabular}

*Títulos idênticos para um ou mais sorovares. 
Quanto a pesquisa de anticorpos anti-Leptospira spp., foram detectadas reações em $32,9 \%$ (29/88) dos soros. Vinte e uma $(60 \%)$ das 35 propriedades apresentaram ao menos um animal reagente. Do total de amostras positivas, houve $4(13,8 \%)$ casos de coaglutinação. Os sorovares Australis, Hardjo, Icterohaemorrhagiae e Tarassovi ocorreram apenas uma vez. A Tabela 2 apresenta os sorovares e as freqüências detectadas com suas respectivas titulações.

Quanto ao Parvovírus suíno, foram detectadas reações na $\mathrm{IH}$ em $7,7 \%(8 / 104)$ dos soros testados, oriundos de $5(10,2 \%)$ das 49 propriedades estudadas. Uma amostra apresentou título de 32 , enquanto que duas apresentaram reações de título 128 e quatro de título 256. Não foram observadas reações positivas na pesquisa de anticorpos contra Pestivírus e Herpesvírus suínos.

\section{DISCUSSÃO}

O presente estudo pesquisou de maneira pioneira a presença de anticorpos contra agentes bacterianos e virais, sejam zoonóticos ou não, em suínos criados em propriedades de agricultura familiar no Município de Monte Negro, RO, na Amazônia Ocidental Brasileira.

A ausência de reações positivas paraBrucellaspp. mediante o emprego das técnicas de SAL e 2-ME, confirmaram a baixa freqüência detectada previamente no AAT $(0,9 \%)$. Poucos levantamentos sorológicos de brucelose suína foram realizados no Brasil, sendo que o último dado oficial apresentado pelo Ministério da Agricultura, Pecuária e Abastecimento refere-se ao ano de 1995, no qual demonstrouse a ocorrência de $0,56 \%$ (BRASIL, 2000).

Neste estudo, $60 \%$ das propriedades apresentaram no mínimo um suíno infectado por Leptospira spp., com freqüência total observada nos animais de $32,9 \%(29 / 88)$. Como a amostragem deste inquérito foi realizada por conveniência, os resultados não podem ser interpretados como indicadores de prevalência, entretanto, fornecem informações sobre as variantes sorológicas que atuam na região. Os sorovares Castellonis, Bratislava e Canicola foram os mais freqüentes, a despeito de variantes mais comuns detectadas em suínos de outras localidades como Icterohaemorrhagiae, Pomona e Autumnalis, em alguns estados das regiões Nordeste, Centro-Oeste, Sudestee Sul do Brasil (FAVEro etal., 2002). A presença do sorovar Castellonis fundamenta-se na presença de roedores (reservatório), enquanto que os sorovares Bratislava e Canicola são mantidos pelos próprios suínos e cães respectivamente (estes praticamente com livre acesso às diversas criações animais)
(RADOstits et al.,2000). Os títulos detectados no ensaio sorológico apresentaram-se baixos, variando de 100 a 800, semelhante aos achados por Azevedo et al. (2006), que estudaram a presença da infecção em matrizes de propriedades tecnificadas da região sudeste do Brasil.

Foi observada baixa freqüência de anticorpos contra PVS (7,7\%). Em estudo semelhante, RodRIGUEZ et al. (2003) detectaram $90 \%$ de suínos reagentes no Município de Uruará, PA, Amazônia Oriental Brasileira, onde as propriedades estudadas também tinham as características de agricultura familiar, não tecnificadas e sem controle sanitário adequado. Entretanto, os resultados em Monte Negro, RO, apontam para uma baixa circulação do PVS na região, podendo ser justificada pela relativa distância dos centros produtores de suínos, já que a parvovirose suína tende a ser mais freqüente em regiões com alta densidade animal.

Nãoforamobservadosanimaissororeagentespara Pestivírus suíno. São escassos os dados referentes a PSC em estados da região norte do Brasil, com exceção doEstado de Tocantins, o qual ézona livre dePSC. Em 1995, os estados da região norte do Brasil não apresentavam propriedades afetadas ou casos de PSC (BRASIL, 2000). Na região estudada, verificou-se uma estreita proximidade entre o local de criação dos suínos e mata peridomiciliar, além dos relatos constantes dos habitantes locais sobre a presença de suínos selvagens nas proximidades das propriedades, $\mathrm{o}$ que poderia atuar como reservatório para os suínos domésticos. Aparentemente estas condições não parecem desempenhar papel relevante, dado que não foram identificados animais sororeagentes. Da mesma forma que a PSC, parece não haver ocorrência de herpesvirus suíno na região, pois não foram detectados anticorpos contra o vírus da DA. Infecções pelo Herpesvírus suíno têm sido relatadas em regiões de alta produção suína, pois a manutenção viral é facilitada pela aglomeração e movimentação de animais entre locais (GROFF et al., 2005).

Os resultados sugerem pouca ou nenhuma circulação dos vírus pesquisados no rebanho suíno do Município de Monte Negro, mesmo sendo praticado sem tecnologia e com controle sanitário inadequado. Por outro lado, aLeptospira spp. encontra-se presente na região, caracterizando promiscuidade entre as espécies animais criadas nas propriedades. Diante de tais resultados e do manejo zootécnico adotado, reúnem-se, portanto, condições para a ocorrência de surtos epidêmicos com possíveis conseqüências desastrosas para a região. Estudos epidemiológicos futuros, nos suínos domésticos e selvagens, devemser realizados a fim de estabelecer medidas profiláticas e estratégicas para o controle desses agentes nos rebanhos suínos da região. 


\section{AGRADECIMENTOS}

A Fundação de Amparo a Pesquisa do Estado de São Paulo (processo 01/11401-9 coordenado pela Prof. Dra. Solange M. Gennari) pelos recursos destinados a este estudo ea Agência Paulista de Tecnologia dos Agronegócios (processo SIGA 2161, coordenado pelo PqC Dr. Daniel M. Aguiar). Ao Conselho Nacional de Desenvolvimento Científico e Tecnológico (CNPq) pela concessão de bolsa de produtividade científica aos Professores Dr. Marcelo B. Labruna, Silvio A. Vasconcellos e Solange M. Gennari.

\section{REFERÊNCIAS}

Aguiar, D.M.; Gennari, S.M.; Cavalcante, G.T.; Labruna, M.B.; Vasconcellos, S.A.; Rodrigues, A.A.R.; Moraes, Z.M.; CAMARGO, L.M.A. Seroprevalence of Leptospira spp. incattle from MonteNegro Municipality, Western Amazon, Brazil. Pesquisa Veterinária Brasileira, v.26, n.2, p.102-104, 2006.

Alton, G.G., Jones, L.M., Pietz, D.E. Las técnicas de laboratorios en la brucellosis. 2.ed. Ginebra:FAO/WHO, 1976.p.173.

Azevedo, S.S.;SOTO, R.M.;MORAIS,Z.M.;P INHEIRO,S.R.; VuAdEN, E.R.; Batista, C.S.A.; Souza, G.O.; Delbem, A.C.B.; GonÇAles, A.P.; Vasconcellos, S.A. Frequency of antiLeptospires agglutinins in sows from a swine herd in the Ibiúna municipality, State of São Paulo, Brazil. Arquivos do Instituto Biológico, São Paulo, v.73, n.1, p.97-100, 2006. Disponível em: Łttp://www. biologico.sp.gov.br/ARQUIVOS/V73_1/ azevedo.PDF>. Acesso em: 20 jun. 2006.

Brasil. Boletim de Defesa Sanitária Animal, Brasília, D.F.: Ministério da Agricultura, Agropecuária e Abastecimento. Defesa Sanitária Animal, v.28, n.1/4, 1995.

Camargo, L.M.A.;Moura, M.M.;E ngracia, V.;P agotto, R.C.; Basano, S.A.; Pereirada Silva, L.H. A rural community in a Brazilian Western Amazonian region: some demographic and epidemiological patterns. Memórias do Instituto Oswaldo Cruz, v.97, p.193-195, 2002.

Cavalcante, G.T; Aguiar, D.M.; Ghiebao, D.P.; Dubey, J.P.; Ruiz, V.L.A.; D iAs, R.A.; C amargo, L.M.A.; L abruna, M.B.; GenNARI, S.M. Seroprevalence of Toxoplasma gondii antibodies incats and pigs from rural Western Amazon, Brazil. Journal of Parasitology, v.92, n.4, p.863-864, 2006.

Cole Junior, J.R.; Sulzer, C.R.; Pursell, A.R. Improved Microtechnique for the Leptospiral Microscopic Agglutination Test. Applied Microbiology, v.25, p.970980, 1973

Cunha, E.M.S.; NASSAR, A.F.C.; LARa, M.C.C.S.H.; Bersano, J.G.; Villalobos, E.M.C.; Lourenço, A.T.A. Detecção de anticorpos contra o Vírus da Doença de Aujeszky (VDA) em Javalis (Sus scrofa) no estado de São Paulo, Brasil: Dados preliminares. Arquivos do Instituto Biológico, São Paulo, v.70, 2003. Suplemento Trabalho apresentado na REUNIÃO ANUAL DO INSTITUTO BIOLÓGICO, 16., 2003, São Paulo. Resumo 129.

FAVero, A.C.M.; Pinheiro, S.R.; Vasconcellos, S.A.; MoraIS, Z.M.; Ferreira, F.; Ferreira Neto, J.S. Sorovares de leptospiras predominantes em exames sorológicos de bubalinos, ovinos, caprinos, eqüinos, suínos ecães de diversos estados brasileiros. Ciência Rural, v.32, n.4, p.613-619, 2002.

Galton, M.M.; Sulzer, C.R.; Santa Rosa, C.A.; Fields, M.J. Application of a Microtechnique to the Agglutination Test for Leptospiral Antibodies. Applied Microbiology, v.13, p.81-85, 1965.

GrofF, F.H.S.;MerLo, M.A.;Stoll, P.A.; StePAN, A.L.; Weiblen, R.; FLORES, E.F. Epidemiologia e controle dos focos da doença de Aujeszky no Rio Grande do Sul, em 2003. Pesquisa Veterinária Brasileira, v.25, n.1, p.25-30, 2005.

Homem, V.S.F.,Heinemann,M.B.,Moraes,Z.M., V asconcellos, S.A., Ferreira, F., Ferreira Neto, J.S. Estudo epidemiológico da leptospirose bovina e humana na Amazônia Oriental brasileira. Revista da Sociedade Brasileira de Medicina Tropical, v.34, p.173-180, 2001.

INCRA. Instituto Nacional de Colonização e Reforma Agrária (Brasil). Novo retrato da agricultura familiar: o Brasil redescoberto. Disponívelem: <http://www.incra.gov. $\mathrm{br} /$ sade/produtos.asp $>$. Acesso em: 20 jun. 2006.

Joo, H.S.; Donaldson-Wood, C.R.; bHnson, R.H. A standardized haemmaglutination inhibition test for Porcine Parvovirus antibody. Australian Veterinary Journal, v.52, p.422-424, 1976.

Kroef, S.S.; Cunha, E.M.S.;Silva, B.G.M.; Racz, M.L.; Kotait, I. Comparação entre o ensaio imunoenzimático (ELISA) e o teste de soroneutralização (SN) para deteç̧ão de anticorpos contra o vírus da doença de Aujeszky em suínos. In: REUNIÃO ANUAL DO INSTITUTO BIOLÓGICO, 5., 1992, São Paulo, SP.Resumos. São Paulo: Instituto Biológico, 1992. p.29. Resmo 058

LaU, H.D.; TOURRAND, J.F.; VeIGA, J.B.; HOMEM, V.S.F.; SimÃo Neto, M. Cattlehealth and public well being in frontier áreas of the Brazilian Amazon. In: INTERNATIONAL CONGRESSOF ANIMALHYGIENE,9.,1997, Helsink, Finlândia. Proceedings. Helsink, 1997. p.7.

Radostits, O.M.; Gay, C.C.; Blood, D.C.; HinchclifF, K.W Veterinary Medicine, 9.ed.Philadelphia:W.B.Saunders, 2000, p.1877.

Rodriguez, C.A.R.; Homem, V.S.F.; HeInEMANn, M.B.; FerReira NETO, J.S.; RICHTZENHAIN,L.J.;SOARES, R.M. Soroprevalência de anticorpos anti-Parvovírus suíno em suínos do município de Uruará, Estado do Pará. Arquivos do Instituto Biológico,SãoPaulo,v.70,n.4,p.501-503,2003.Disponível em: <http://www.biologico.sp.gov.br/ARQUIVOS/ V70_4/rodriguez.pdf>.Acesso em: 20 jun. 2006.

Roxo, E.; Bersano, J.G.; Portugal, M.A.S.C. Brucella suis em diversas espécies de animais numa mesma propriedade rural. Arquivos do Instituto Biológico, São Paulo, v.63, n.1, p.11-14, 1996.

Toscano, L.F. Agricultura familiar e seu grande desafio. Diário de Votuporanga, v.50, n. 12.769, p.2, 2003.

Veiga, J.B. TourRand, J.F.; Quanz, D.A. A pecuária na fronteira agrícola da Amazônia. O caso do município de Uruará-PA na transamazônica. Boletim de Pesquisa da EMBRAPA-CPATU, v.87, p.61, 1996.

Recebido em 31/7/06

Aceito em 27/9/06 